\title{
A 23-year-old man with left lung atelectasis treated with a targeted segmental recruitment maneuver: a case report
}

\author{
Alen Protić*, Matej Bura and Kazimir Juričić
}

\begin{abstract}
Background: Lung atelectasis are nonventilated parts of lung tissue and occur as a result of the collapse of the pulmonary parenchyma (alveoli). Various therapeutic procedures for inflating the collapsed pulmonary parenchyma, such as bronchial aspiration and/or standard recruitment maneuvers, are not always successful.

Case presentation: We report a case of a 23-year-old Croatian man with a parapharyngeal abscess on the left side of the neck with spreading of infection in the mediastinum and left side of the thorax and consequent major atelectasis of the left lung. The patient was mechanically ventilated. We decided to apply a new method in which a pulmonary artery catheter was placed (guided by bronchoscope) on the entrance to the lower left bronchus. The pulmonary artery catheter balloon was inflated to achieve bronchial closure. Using another respirator, we ventilated the affected lobe separately with continuously high pressure of $30 \mathrm{cmH}_{2} \mathrm{O}$. After 30 minutes, we removed the pulmonary artery catheter from the lower left bronchus and placed it in the upper left bronchus and repeated the procedure. Our method allowed a significantly longer duration (30 minutes) of continuously high pressure of 30 $\mathrm{CmH}_{2} \mathrm{O}$ separately to only one of the total of five lobes of the lungs while the other four lobes were simultaneously ventilated continuously with protective ventilation mode.
\end{abstract}

Conclusion: Use of a pulmonary artery catheter and two respirators in our patient's case proved to be a successful method for recruiting the atelectatic lung while maintaining protective ventilation of the lung segments without atelectasis.

Keywords: Lung atelectasis, Segmental recruitment, Prolonged recruitment

\section{Background}

Lung atelectasis are nonventilated parts of lung tissue and occur as a result of the collapse of the pulmonary parenchyma (alveoli). Usually, it appears in the lower and posterior portions of the lung due to a long duration in supine position, which can enhance an inflammatory process in the lung and result in pneumonia [1]. Lung atelectasis in clinical practice can be treated with bronchoaspiration and continuous positive airway

\footnotetext{
* Correspondence: alen.protic@medri.uniri.hr Department of Anesthesiology and ICU, University Hospital Rijeka, Tome Strizica 3, 51000 Rijeka, Croatia
}

(c) The Author(s). 2020 Open Access This article is licensed under a Creative Commons Attribution 4.0 International License, which permits use, sharing, adaptation, distribution and reproduction in any medium or format, as long as you give appropriate credit to the original author(s) and the source, provide a link to the Creative Commons licence, and indicate if changes were made. The images or other third party material in this article are included in the article's Creative Commons licence, unless indicated otherwise in a credit line to the material. If material is not included in the article's Creative Commons licence and your intended use is not permitted by statutory regulation or exceeds the permitted use, you will need to obtain permission directly from the copyright holder. To view a copy of this licence, visit http://creativecommons.org/licenses/by/4.0/ The Creative Commons Public Domain Dedication waiver (http://creativecommons.org/publicdomain/zero/1.0/) applies to the data made available in this article, unless otherwise stated in a credit line to the data.
(CPAP) during spontaneous breathing or positive end-expiratory pressure (PEEP) during mechanical ventilation [2]. Both methods have an effect on the entire pulmonary parenchyma, including nonatelectatic parts of the lung. By increasing the basic PEEP level to 10 or $12 \mathrm{cmH}_{2} \mathrm{O}$ in mechanically ventilated patients, trying to prevent atelectasis, the side effects of overstretching unaffected alveoli and increasing intrathoracic pressure also occur. Barotrauma and volutrauma of the nonatelectatic lung parenchyma may result, as well as hemodynamic instability due to decreased cardiac output $[3,4]$. A more invasive approach to resolving lung tissue atelectasis in the last 15 years has been the recruitment 
maneuver (inspiratory hold) for 30 to 40 seconds with a positive pressure of 30 to $40 \mathrm{cmH}_{2} \mathrm{O}$, where open alveoli are inflated more extensively and the effect on closed alveoli is questionable.

\section{Case presentation}

A 23-year-old Croatian man without any significant past medical history was admitted to our intensive care unit (ICU) due to a parapharyngeal abscess on the left side of the neck with spreading of infection in the mediastinum and the left side of the thorax. Urgent surgery was performed with incision of the parapharyngeal abscess, neck dissection, and left side thoracotomy with incision and drainage of the mediastinum and thorax. In the postoperative period in the ICU, the patient was sedated and mechanically ventilated with antibiotic therapy according to microbiological findings (blood, urine, bronchoalveolar lavage, and tissue sample taken during surgery). After the first surgery, Streptococcus mitis was isolated from the parapharyngeal abscessus. In the second surgery, Staphylococcus sp. was isolated from the mediastinal and neck swab wounds. From the beginning (upon admission to the ICU), the patient was treated with meropenem and linezolid. During the second week of treatment, he started to develop a nosocomial infection of the lung caused by multiresistant Pseudomonas aeruginosa, which was treated with ceftolozane/tazobactam $3 \times 3 \mathrm{~g}$ intravenously. In the next 10 days, control computed tomographic (CT) scans of the neck and chest showed progression of mediastinal infiltrates and the formation of organized pleural effusion on the left side that required additional surgery. Due to atelectasis of the left lung that persisted during the second week of treatment in the ICU, bronchoscopy with bronchoaspiration and recruitment maneuvers were performed several times. Residual pleural effusions were drained several times before and after weaning procedures with a smallbore pleural catheter and Seldinger technique. On the 30th day of the patient's illness, sedation was stopped, and the patient awoke promptly. $\mathrm{He}$ was hemodynamically stable and ready for weaning, which was successfully done in the next 24 hours. When the patient was extubated and started to breathe spontaneously, we enhanced his active physical therapy in combination with a cough assist device (CoughAssist E70; Philips Respironics, Hamburg, Germany). After the weaning procedure, the patient was fully conscious and hemodynamically stabile with blood pressure $115 / 70 \mathrm{mmHg}$, heart rate of 86 beats/minute, and body temperature of $36.7^{\circ} \mathrm{C}$. The patient was spontaneously breathing with oxygen saturation $\left(\mathrm{SpO}_{2}\right)$ of $94 \%$, fraction of inspired oxygen $\left(\mathrm{FiO}_{2}\right)$ of
$50 \%$, partial pressure of oxygen $\left(\mathrm{PaO}_{2}\right)$ of $9.19 \mathrm{kPa}$, carbon dioxide pressure $\left(\mathrm{pCO}_{2}\right)$ of $5.7 \mathrm{kPa}$, and $\mathrm{PaO}_{2} /$ $\mathrm{FiO}_{2}$ ratio of 138, but almost no rising of the left side of the thorax and no breath sounds on the same side.

We performed lung ultrasound, which showed atelectasis of the major part of the left lower lobe and the posterior part of the upper lobe on the 34th day of the patient's stay in the ICU. We used electrical impedance tomography (Dräger PulmoVista 500; Dräger, Lübeck, Germany) as additional diagnostic support for the ultrasound, which confirmed reduced air entrance in the major part of the left lung. Finally, according to local protocol, we performed a CT scan of the chest, which confirmed previous findings of complete atelectasis of the left lower lobe and major atelectasis of the left upper lobe (Fig. 1).

We decided to apply a new method whereby we used different experiences of single-lung ventilation respecting all basic principles of various types of mechanical ventilation. Our trial, which we named "targeted segmental recruitment," was one of the last attempts to avoid the proposed life-threatening surgical reduction of the lung parenchyma in our young patient. His Acute Physiology and Chronic Health Evaluation II (APACHE II) score upon admission was 7, and his Sequential Organ Failure Assessment (SOFA) score upon admission was 6. On the day before we performed the segmental recruitment maneuver, his APACHE II score was 12, and his SOFA score was 6 . His procalcitonin level on the day before segmental recruitment maneuver was $0.171 \mu \mathrm{g} / \mathrm{L}$.

The patient was analgosedated, intubated with the Univent $8.5-\mathrm{mm}$ tube (tube with integrated endobronchial blocker; Vitaid, Lewiston, NY, USA), and mechanically ventilated. We removed the endobronchial blocker and replaced it with a pulmonary artery (PA) catheter. With the help of a bronchoscope, using a loop through the working channel of the bronchoscope, the PA catheter was placed in the entrance to the lower left bronchus, and the PA catheter balloon was inflated to achieve bronchial closure. Using the appropriate connectors, we connected the PA catheter to the second ventilator (Dräger Evita 2) and applied $30 \mathrm{cmH}_{2} \mathrm{O}$ of pressure of the $30 \%$ oxygenated air in CPAP ventilation mode for 30 minutes. The decision for the pressure of $30 \mathrm{cmH}_{2} \mathrm{O}$ was made on the basis of the fact that pressures higher than $35 \mathrm{cmH}_{2} \mathrm{O}$ are associated with barotrauma and the clinical appearance of pneumothorax [5]. The right lung and the upper lobe of the left lung were ventilated the entire time by controlled mechanical ventilation with protective ventilation parameters using the Dräger Evita $\mathrm{XL}$ ventilator. After 30 minutes, we removed the PA catheter from the lower left bronchus and placed it in the upper left bronchus with the described procedure and repeated the CPAP maneuver. Again, the right lung 


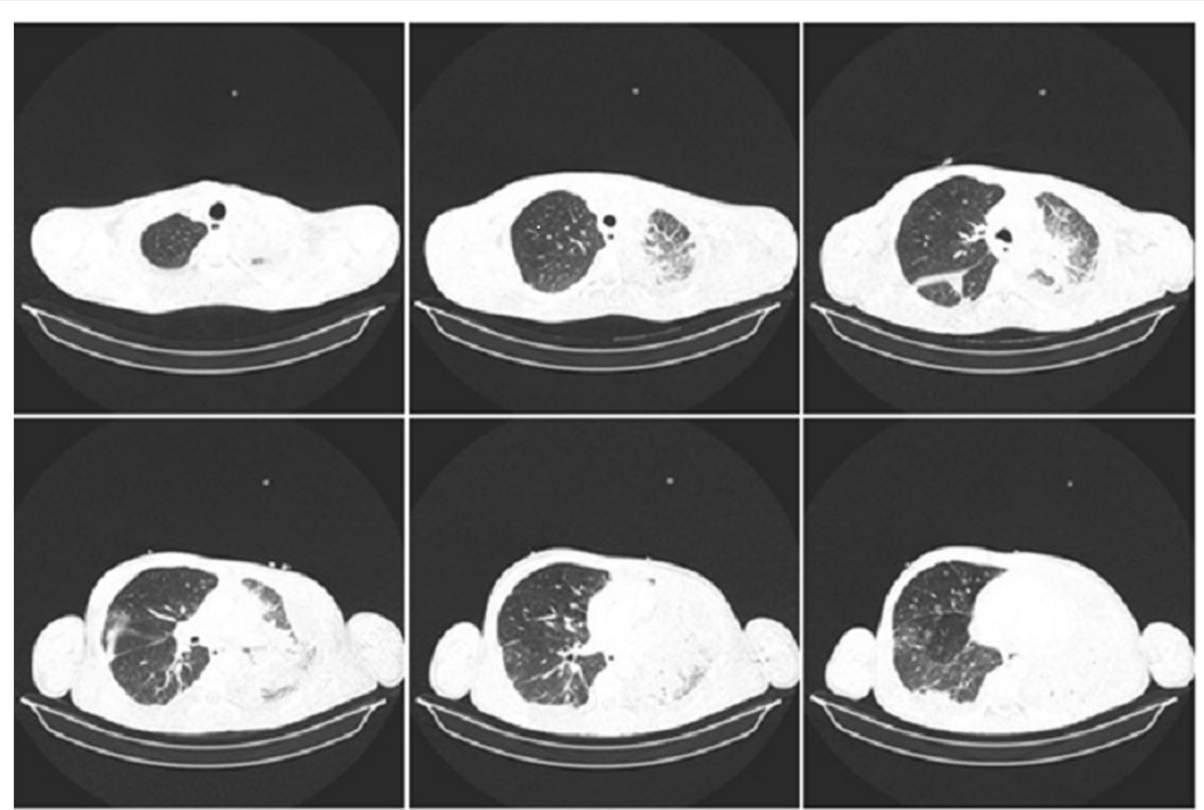

Fig. 1 Computed tomographic scan of the chest of the patient on the 34th day of his stay in the intensive care unit

and the lower lobe of the left lung were simultaneously ventilated by controlled mechanical ventilation with protective ventilation parameters. Within the next 12 hours of the performed procedure, the patient was awakened and extubated. After the targeted segmental recruitment, he was breathing spontaneously with improved clinical parameters as well as better rising of the left side of the thorax with audible respiratory sounds on the left side.
The PulmoVista 500 monitoring was applied continuously, and better ventilation of the left lung was noted in the first hours after the procedure. In the next 48 hours, we applied the CoughAssist device to the patient, and he was encouraged to cough. After 48 hours (36th day of treatment), a CT scan of the thorax was performed, indicating significantly better ventilation of the left lung (Fig. 2). During and after the procedure, $\mathrm{SpO}_{2}$, end-tidal

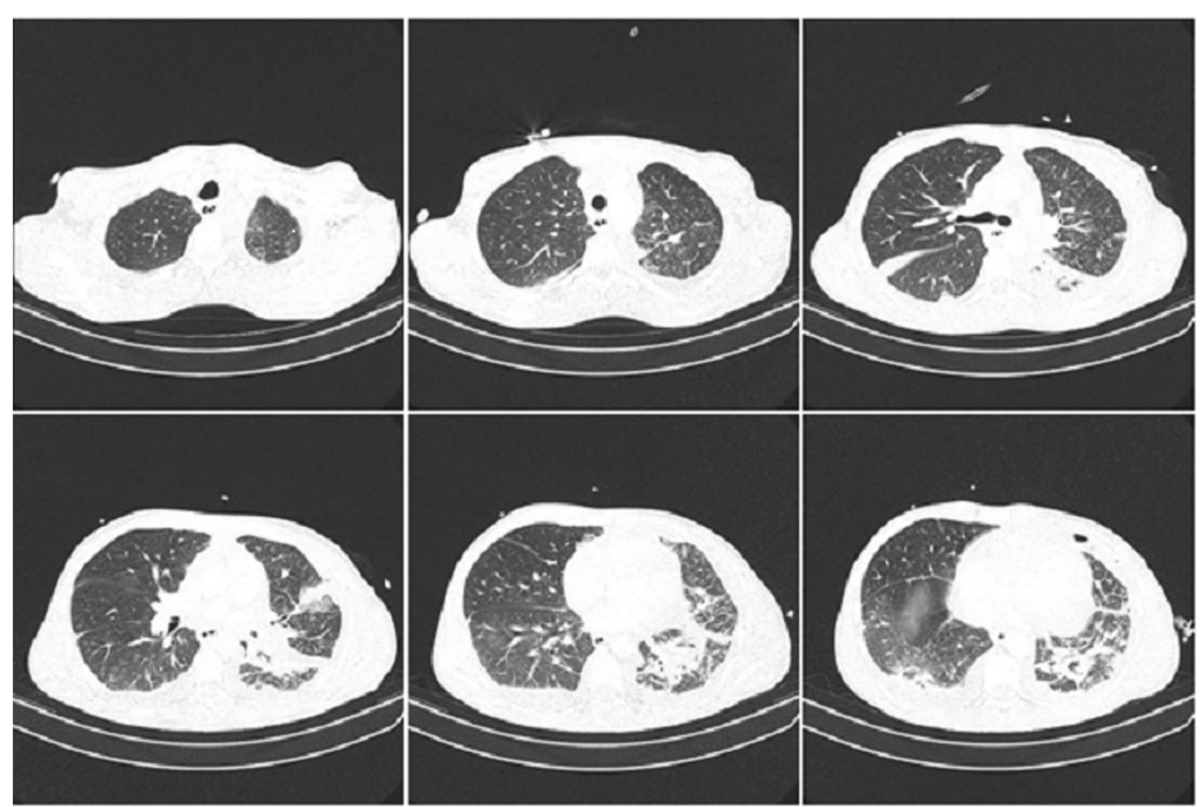

Fig. 2 Computed tomographic scan of the chest of the patient after targeted segmental recruitment (36th day of stay in the intensive care unit) 
carbon dioxide $\left(\mathrm{EtCO}_{2}\right)$, invasive blood pressure, and pulse were monitored. The patient did not have any significant decrease in $\mathrm{SpO}_{2}$ or increase in $\mathrm{EtCO}_{2}$, nor did he have hemodynamic instability or changes in heart rhythm. Before and after the procedure, arterial blood gas analyses were performed as part of routine laboratory processing (Table 1 ). The patient was discharged to home 49 days after admission, and he was mobile on his own with stabile hemodynamic and respiratory status and without signs of infection.

\section{Discussion}

The collapse of the pulmonary parenchyma is a problem that became more visible when diagnostic methods such as CT scanning and ultrasound became more commonly used in clinical practice. In the past few decades, many good ideas have found useful application, such as increasing the basic PEEP level, prone positioning of the patient, recruitment maneuver with inspiratory hold, and others. The recruitment maneuver has become standard practice in many ICUs all over the world, despite a well-known effect being overstretching of unaffected alveoli with a questionable effect on collapsed alveoli. A study that used a recruiting maneuver in patients with pneumonia combined with acute respiratory distress syndrome or the need for vasopressors showed increased mortality, which confirmed the potential harm of recruiting maneuvers [6]. Unilateral recruitment using an endobronchial blocker has been described in the literature as a successful method of treating atelectasis [7]. The endobronchial blocker was used to protect the left lung while recruitment of the right lung atelectasis was applied for 3 minutes. In this case report, step-forward was done regarding duration of the recruitment maneuver, despite the fact that healthy lung was not ventilated in that period.

In our clinical practice, we often use the CPAP recruitment maneuver, usually with $40 \mathrm{cmH}_{2} \mathrm{O}$ pressure for 40 seconds if the patient does not have any hemodynamic instability. If hemodynamic instability is present, we shorten the period of inflation to 20 seconds. Our patient was a healthy person with no comorbidities and showed no emphysematous or other changes besides pneumonic infiltration in the lung parenchyma, which can cause barotrauma to the lungs. In the literature, recruitment maneuvers with pressure greater than 30 $\mathrm{cmH}_{2} \mathrm{O}$ are often described. In cases of chronic changes in the lung, we will surely reduce the time of the inflation. After the extubation, we usually encourage secretion removal with aggressive physical therapy and the CoughAssist device. Bronchoaspiration before extubation is our routine procedure in these patients. Therefore, we concluded that we had a patient who had undergone many repeated therapeutic procedures, all with the purpose of inflating the left lung (bronchial aspiration, standard recruitment maneuvers, thoracic drainage), and surgical lung resection became an option for treatment. Therapeutic options according to the new idea of targeted segmental recruitment as a lifesaving procedure were discussed with the patient's mother, and she signed the informed consent.

Our method allowed a significantly longer duration (30 minutes) of continuously high pressure of $30 \mathrm{cmH}_{2} \mathrm{O}$ separately to only one of the five total lobes of the lungs, which meant significantly less increase in the total intrathoracic pressure in comparison with a classic recruitment maneuver. The targeted segmental recruitment procedure significantly reduces the risk of barotrauma of healthy alveoli as well as the negative effect on the hemodynamic stability of patients compared with conventional recruitment maneuvers.

\section{Conclusion}

Targeted segmental recruitment with the help of a PA catheter and the use of two respirators in our patient's case proved to be a successful method for recruiting the atelectatic lung while maintaining protective ventilation of the lung segments without atelectasis.

Table 1 Findings of blood gas analysis before extubation (30th day), before (34th day) and after (35th and 36th days) targeted segmental recruitment

\begin{tabular}{|c|c|c|c|c|c|}
\hline & 30th day & 34th day & & 35th day & 36th day \\
\hline $\mathrm{FiO}_{2}(\%)$ & 40 & 50 & & 40 & 40 \\
\hline $\mathrm{pH}$ & 7.44 & 7.39 & & 7.44 & 7.44 \\
\hline $\mathrm{PaO}_{2}(\mathrm{kPa})$ & 9.9 & 9.19 & & 12.3 & 14.5 \\
\hline $\mathrm{PaCO}_{2}(\mathrm{kPa})$ & 4.6 & 5.7 & \multirow{5}{*}{$\begin{array}{l}\text { Targeted segmental } \\
\text { recruitment }\end{array}$} & 5.2 & 5.1 \\
\hline $\mathrm{PaO}_{2} / \mathrm{FiO}_{2}$ & 187.25 & 137.86 & & 230.64 & 271.90 \\
\hline $\mathrm{SpO}_{2}(\%)$ & 95.2 & 94.2 & & 97.2 & 98.2 \\
\hline Lactate $(\mathrm{mmol} / \mathrm{L})$ & 0.9 & 0.8 & & 0.8 & 0.7 \\
\hline CRP & 277.2 & 101.6 & & 96.1 & 97.3 \\
\hline
\end{tabular}

Abbreviations: CRP C-reactive protein, $\mathrm{FiO}_{2}$ Fraction of inspired oxygen, $\mathrm{PaO}_{2}$ Partial pressure of arterial oxygen, $\mathrm{PaCO}_{2} \mathrm{Carbon}$ dioxide pressure, $\mathrm{SpO}$ Oxygen saturation 


\section{Abbreviations}

APACHE II: Acute Physiology and Chronic Health Evaluation II;

CPAP: Continuous positive airway pressure; $\mathrm{CT}$ : Computed tomographic;

$\mathrm{EtCO}_{2}$ : End-tidal carbon dioxide; ICU: Intensive care unit; PA: Pulmonary artery; PEEP: Positive end-expiratory pressure; SOFA: Sequential Organ Failure Assessment

\section{Acknowledgements}

Not applicable.

\section{Authors' contributions}

AP came up with the idea for the lifesaving procedure explained in this case report. AP performed the procedure and was a major contributor in writing the manuscript. $\mathrm{KJ}$ helped to carry out the process and to develop the idea. $\mathrm{MB}$ analyzed and interpreted the patient data and was a contributor to the writing of the manuscript. All authors read and approved the final manuscript.

\section{Authors' information}

AP is a professor in the School of Medicine, University of Rijeka, and head of the anesthesiology and ICU clinic, University Hospital Rijeka, Rijeka, Croatia. $\mathrm{KJ}$ is head of the ICU in the anesthesiology and ICU clinic. MB is a resident in the anesthesiology and ICU clinic.

\section{Funding}

No financial support and sponsorship.

\section{Availability of data and materials}

The datasets used and/or analyzed during the current study are available from the corresponding author on reasonable request. All data generated or analyzed during this study are included in this published article.

\section{Ethics approval and consent to participate}

This manuscript is a case report about a lifesaving procedure. Because it involves human data, the patient signed a consent form for medical information/data about himself to be published.

\section{Consent for publication}

Written informed consent was obtained from the patient for publication of this case report and any accompanying images. A copy of the written consent is available for review by the Editor-in-Chief of this journal.

\section{Competing interests}

The authors declare that they have no competing interests.

Received: 2 March 2020 Accepted: 25 May 2020

Published online: 24 June 2020

\section{References}

1. Woodring JH, Reed JC. Types and mechanisms of pulmonary atelectasis. Thorac Imaging. 1996;11:92-108.

2. Constantin JM, Cayot S, Futier E, Bazin JE. Recruitment maneuvers in acute respiratory distress syndrome. Reanimation. 2004;13:29-36.

3. Protsenko D, Magomedov R, Ignatenko O, Yaroshetskiy Al, Gelfand B. Hemodynamics effects of recruitment maneuver. Crit Care. 2012;16:108.

4. Slutsky AS, Ranieri VM. Ventilator-induced lung injury. N Engl J Med. 2013; 369:2126-36.

5. Thierry G, Hospital HM, Créteil C. Relationship between ventilatory settings and barotrauma in the acute respiratory distress syndrome. Intensive Care Med. 2002;28:406-13.

6. Zampieri FG, Costa EL, Iwashyna TJ, et al. Heterogeneous effects of alveolar recruitment in acute respiratory distress syndrome: a machine learning reanalysis of the Alveolar Recruitment for Acute Respiratory Distress Syndrome Trial. Br J Anaesth. 2019;123:88-95.

7. Purtuloglu T, Eksert S, Simsek F, Sizlan A, Cosar A. A new treatment modality for unilateral atelectasis: recruitment maneuver with endobronchial blocker. Indian J Crit Care Med. 2013;17:240-2.

\section{Publisher's Note}

Springer Nature remains neutral with regard to jurisdictional claims in published maps and institutional affiliations.

Ready to submit your research? Choose BMC and benefit from:

- fast, convenient online submission

- thorough peer review by experienced researchers in your field

- rapid publication on acceptance

- support for research data, including large and complex data types

- gold Open Access which fosters wider collaboration and increased citations

- maximum visibility for your research: over $100 \mathrm{M}$ website views per year

At $\mathrm{BMC}$, research is always in progress.

Learn more biomedcentral.com/submissions 